\title{
Chronic Alcohol Use and Accompanying Noncommunicable Diseases
}

1 Israel Oluwasegun Ayenigbara

1 Doctoral Candidate, School and Community Health Education Unit, Department of Health Education, University of Ibadan, Ibadan, Nigeria

Article received: 23.01.2020.

Article accepted: 24.06.2020.

https://doi.org/10.24141/2/4/2/8

Author for correspondence:

Israel Oluwasegun Ayenigbara

School and Community Health Education Unit, Department of Health Education, University of Ibadan

Ibadan, Nigeria

E-mail: histrealite2647@gmail.com

Keywords: pattern, chronic, alcohol use, noncommunicable diseases

\section{Abstract}

Introduction. Heavy and chronic alcohol use connotes frequent, continuous and persistent consumption of alcoholic drinks over an extended period of time. Importantly, heavy consumption of alcohol causes many health problems to the drinker and the society at large, as over $5.1 \%$ of the global burden of morbidity and injuries are attributable to alcohol usage alone.
Aim. The purpose of this study is to identify some of the noncommunicable diseases that are associated with chronic alcohol consumption through a systematic and narrative review, with detailed descriptions of the occurrences.

Methods. A systematic and narrative review of literature that evaluates noncommunicable diseases associated with chronic alcohol consumption was carried out using Google, Medline and databases of major international health organizations. Keywords used as search terms were alcoholism, chronic alcohol use and heavy alcohol use; these terms were matched with occurrences and risk of noncommunicable diseases. Studies included in this review are clinical trials, meta-analyses, randomized controlled trials, and systematic and review articles.

Results. The findings revealed that chronic alcohol use is either a single or joint risk factor for Alzheimer's disease and dementia, arthritis, brain malfunction, cancer (most commonly of the oropharynx, larynx, oesophagus, liver, colon, rectum or breast), chronic obstructive pulmonary disease (COPD), diabetes, epilepsy, heart diseases and cardiovascular diseases, immune system dysfunction, malnourishment and vitamin deficiencies, mood disorders, bipolar disorder and depression, osteoporosis and bone malformation, pancreatitis, and ulcers and gastrointestinal problems.

Conclusion. These findings are background information as they revealed some of the noncommunicable diseases associated with chronic alcohol use. Hence, more and precise long-term cohort studies are necessary for a better understanding of the occurrences and epidemiology of noncommunicable diseases as a result of chronic alcohol use. 


\section{Introduction}

Heavy or chronic alcohol use connotes frequent, continuous and persistent consumption of alcoholic drinks over an extended period of time which is destructive and deleterious to health because it negatively affects the body overall. Alcohol, also known as liquor or ethanol, is a psychoactive substance with a high dependency rate, and has been used in numerous societies and cultures for decades (1). Heavy consumption of alcohol causes many problems to the drinker and the society at large, posing a risk factor for various diseases and infections, as well as causing social and economic burden and harm to other people, for example families, relatives, friends, work associates and strangers (1).

Alcohol abuse can have severe consequences for the abuser (2). When large amounts of alcohol are consumed, the excess builds up in the bloodstream. Afterwards, the heart circulates alcohol throughout the body, leading to alterations in the normal bodily functions, and a single bout of binge-drinking can result in significant bodily impairment, damage, or even death (3). If excessive alcohol consumption occurs consistently, it can lead to the development of many chronic diseases and other serious health problems (3). Statistics suggest that alcohol abuse results in over three million deaths worldwide every year, which represents $5.4 \%$ of all global deaths (1). Furthermore, alcohol abuse is a risk factor for over two hundred diseases and types of injuries (1). Likewise, heavy consumption of alcohol is associated with the risk of developing mental and behavioural disorders, alcohol dependence, major noncommunicable diseases such as liver cirrhosis, some types of cancer and cardiovascular diseases, as well as injuries resulting from violence and traffic accidents (1). Importantly, the consequences for health associated with heavy alcohol intake are enormous, and the focus of this study is on the accompanying noncommunicable diseases that are associated with heavy and chronic alcohol consumption.

\section{The pattern of alcohol use in the world}

According to the World Health Organization (WHO), over $5.1 \%$ of the global burden of morbidity and injury is attributable to alcohol usage, as alcohol consumption causes death and disability relatively early in life (1). In addition, in the age range of 2039 , approximately $13.5 \%$ of total deaths are linked to alcohol (1). In Britain, there were over eight thousand deaths linked to alcohol abuse in 2007 (13.3 per 100.000 population in 2007). Although this was lower than in 2006, it was double the number of recorded deaths in 1991 (6.9 per 100.000 population in 1991) (4). Also, the findings from a study from the United Kingdom revealed that alcohol consumption causes about $4.1 \%$ of cancer cases in the UK $(12.500$ cases per year) (5). In Scotland, the National Health Scheme (NHS) estimated that in 2003 one in every twenty deaths could be linked to alcohol abuse (6). Furthermore, in Scotland, a 2009 report noted that the death rate from alcohol-related diseases was 9,000 , a number three times that of 25 years previously (7).

In Russia, excessive alcohol consumption, especially among men, has recently caused more than half of all the deaths between the ages of 15 and 54 (8). In the United States of America, heavy alcohol use is the fourth leading preventable cause of death, as it results in approximately 88.000 deaths yearly, which includes one in ten overall deaths among adults between the ages of 20 and 64 (3,9). Furthermore, heavy alcohol use alone costs the US government over 249 billion dollars, approximately \$2.05 per drink in 2010 (9).

Chronic alcohol use incorporates binge drinking, heavy drinking and any form of alcohol consumption by pregnant women or anyone under 21 years of age (9). Binge drinking is characterized as the intake of more than three alcoholic drinks on one occasion for a woman, or the intake of more than four consecutive alcoholic drinks for a man, while heavy drinking is characterized as the intake of more than seven alcoholic drinks in a week for a woman, or more than fourteen alcoholic drinks in a week for a man (9).

According to the Centers for Disease Control and Prevention (CDC), more than half of all deaths and three-quarters of the costs due to excessive alcohol consumption are the result of binge drinking (9). It has been further estimated that over 36.5 million of US adults, approximately one in six, binge drink at least once per week, with an average consumption of more than six alcoholic drinks per binge, resulting in an overall consumption of 17 billion binge drinks annually by US adults, approximately 470 binge drinks per an individual binge drinker (9). 


\section{Methods}

A combination of the systematic and the narrative review approach was adopted for this study. A systematic review was used to identify and select viable studies, while a narrative review was used to provide detailed explanations and descriptions of the studies identified. The keywords used as search terms were alcoholism, chronic alcohol use and heavy alcohol use, and these terms were then matched with the occurrences of noncommunicable diseases.

\section{Inclusion and exclusion criteria}

Google and Medline databases were searched extensively, and the studies included in this review are clinical trials, meta-analyses, randomized controlled trials and systematic and review articles. Furthermore, the databases of major national and international health organizations (for example, The World Health Organization and Centers for Disease Control and Prevention) were searched to obtain relevant data for the study.

The researchers also included the full text of articles written in English, while abstracts written in other languages were translated into English. The year of publication was not a criterion in the selection of studies. Afterwards, extensive data screening was performed, and all documents that do not concur with the aims and objectives of the study were excluded in the final analysis to reduce the number of studies.

\section{Papers included in the final analysis}

Upon the entry of the keywords into the databases, thousands of potential articles were obtained. After analysing the titles of the papers, the second step was the analysis of their abstracts. Extensive screening was performed, and the inclusion and exclusion criteria were fully implemented, reducing the number of studies to appropriate numbers. 80 studies were included from the Medline database, while 9 other documents were obtained from other databases. In total, eighty-nine (89) studies were deemed appropriate and were included in this review study for detailed narration.

\section{Chronic alcohol use and noncommunicable diseases}

Excessive consumption of alcohol over a long period of time predisposes an individual to organ and system damage (10). Likewise, extended heavy alcohol use predisposes an individual to the onset of chronic diseases and other serious problems, for instance alcohol use disorder (AUD) and problems with learning, memory and mental health (9,11-14).

\section{Results and discussion}

Alzheimer's disease and dementia: There is an underlying neurobiological link between alcohol use and Alzheimer's disease (AD) (3). This is confirmed by the fact that alcohol use, alcohol abuse and dependence cause cognitive impairment (15). Also, alcohol adds to the cognitive burden seen in dementia through additional mechanisms of neurodegenerative processes and may contribute at various mechanistic points in the genesis and sustenance of AD pathology via neuroinflammation (15).

Heavy alcohol consumption is associated with a faster rate of cognitive decline in AD patients, suggesting that it may accelerate the progression of AD (16). Therefore, drinking habits might alter the course of AD negatively (16). In addition, there is ample evidence of a causal association between alcohol consumption and an earlier Alzheimer's disease age of onset survival (AAOS) and increased $\gamma$-glutamyl transferase blood concentrations (17). Although modest alcohol consumption ( $\leq 12.5 \mathrm{~g} /$ day) is associated with a reduced risk of dementia, with $6 \mathrm{~g} /$ day of alcohol conferring a lower risk than other levels, excessive drinking ( $\geq 38 \mathrm{~g} /$ day) may instead elevate the risk (18).

Finally, long-term consumption of alcohol aggravates cognitive decline, increases the permeability of the blood-brain barrier (BBB), leads to pathomorphological changes and downregulates some related structural proteins (zonula occludens-1, VE-cadherin, and occludin) and functional proteins (major facilitator super family domain-containing protein-2a [Mfsd2a]), low- density lipoprotein receptor-related pro- 


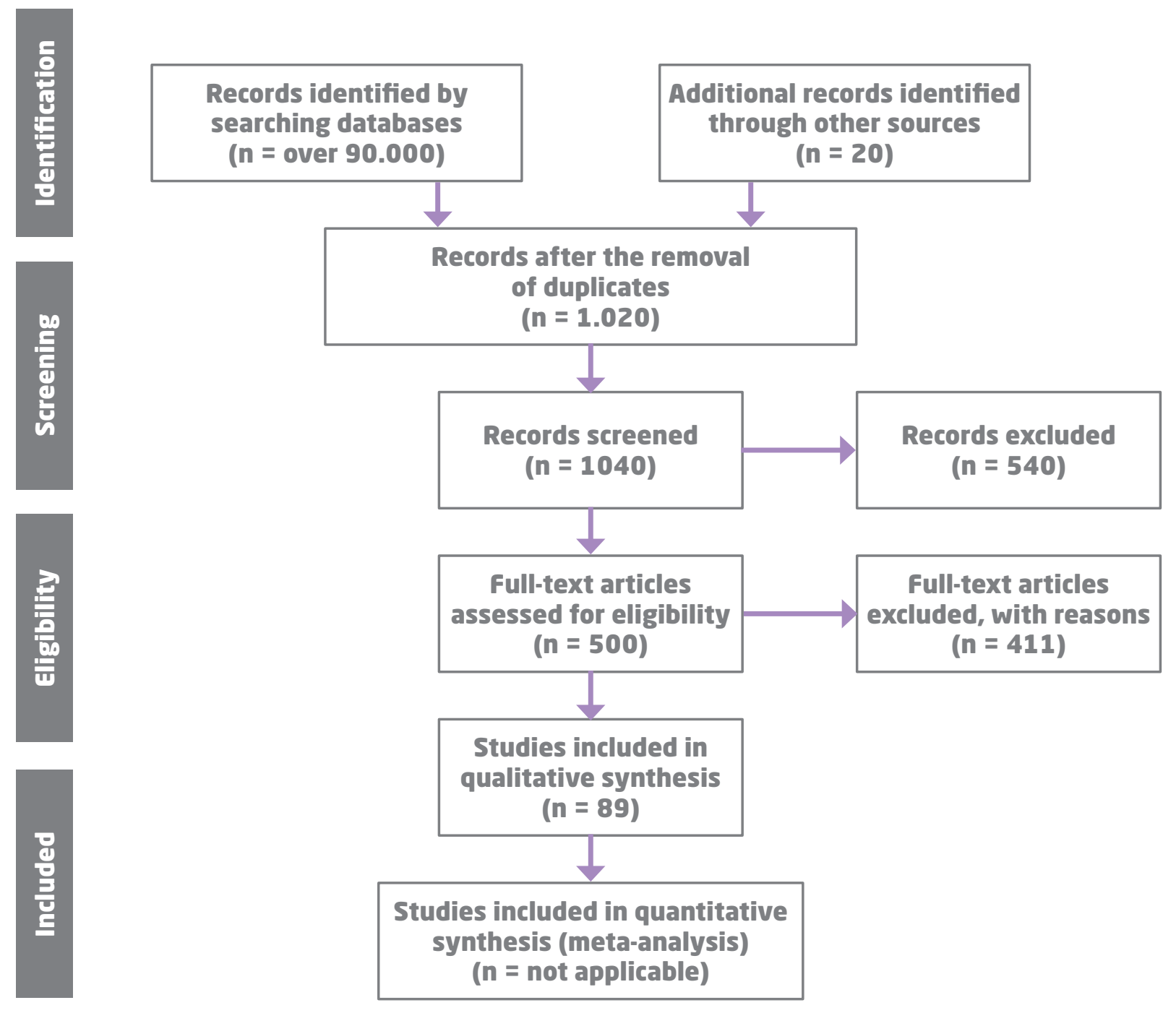

Figure 1. Flow of information through different phases of the systematic review

tein-1 (LRP1), receptor for advanced glycation end products (RAGE), and aquaporin-4 (AQP4) in the BBB (19). Hence, these novel findings suggest that longterm consumption of alcohol induces neural lesions, which is related to the destruction of the integrity of the blood-brain barrier (BBB) (19).

Arthritis: Chronic alcohol consumption is also linked to arthritis (3). A study on alcohol consumption as a predictor of the progression of spinal structural damage in axial spondyloarthritis revealed that drinking alcohol showed a significant correlation with the progression of spinal structural damage for both modified Stoke Ankylosing Spondylitis Spinal Score (mSASSS) and syndesmophyte progression (20). The findings of this study showed the association between alcohol consumption and spinal structural progression in axial spondyloarthritis (axSpA) patients for the first time (20). Also, increased body mass index (BMI) and even moderate alcohol intake were associated with an increased risk of psoriatic arthritis (PsA) in people with psoriasis (21).

Some studies have shown that moderate alcohol consumption offers protection against rheumatoid arthritis (RA). For instance, according to a study on the interplay between alcohol, smoking and human leucocyte antigen (HLA) genes in RA aetiology, the findings revealed that, when compared with nondrinking, low and moderate alcohol consumption was 
dose-dependently associated with a reduced risk of alcohol on anticitrullinated protein antibody (ACPA) positive and ACPA-negative RA, but it was advised that a protective role of alcohol on RA risk must be interpreted with caution from a clinical and public health perspective (22).

Impact on the brain: Alcohol is associated with blurred vision, memory lapses, slurred speech, difficulty walking and slow reaction time, all of which are due to the effect of alcohol on the brain (3). Chronic drinking increases the incidence of intracerebral haemorrhage (ICH), which can have severe consequences. Chronic alcohol abuse also tends to elevate blood pressure, resulting in increased occurrence of hypertensive intracerebral haemorrhage $(\mathrm{HICH})$ and exaggerated $\mathrm{HICH}$-contributed brain injury (23).

Alcohol consumption during pregnancy can produce a variety of central nervous system (CNS) abnormalities in the child, resulting in a broad spectrum of cognitive and behavioural impairments that constitute the most severe and long-lasting effects observed in foetal alcohol spectrum disorders (FASD) (24). The consequences of prenatal alcohol exposure on glial cells, including radial glia and other transient glial structures present in the developing brain, astrocytes, oligodendrocytes and their precursors and microglia contribute to abnormal neuronal development, reduced neuron survival and disrupted brain architecture and connectivity (24). In addition, prenatal alcohol exposure affects iron homeostasis of specific brain areas (prefrontal cortex [PFC]) and the hippocampus, which could be involved in maladaptive cognition (25). Also, past and recent patterns of intermittent heavy alcohol consumption are associated with reduced frontal cortical thickness (i.e. "thinness") of the right mid-anterior cingulate cortex (ACC) and left posterior cingulate cortex (PCC) in emerging adults, but not the parieto-occipital sulcus (POS) (26). While cortical thinness can predate binge drinking, this pattern of maladaptive consumption may have acute neurotoxic effects that interfere with the finalization of neuromaturational processes in the vulnerable frontal cortex, resulting in increased microarchitectural pruning (26).

The findings from a study on the burden of binge and heavy drinking on the brain in adolescents and young adults suggest that altered neural structure and activity in binge- and heavy-drinking youth may be related to the neurotoxic effects of consuming alcohol in large quantities during a highly plastic neurode- velopmental period, which could result in neural reorganization and increased risk for developing alcohol use disorder in the future (27).

Cancer: Chronic alcohol consumption increases the chances of developing different types of cancer, including cancer of the mouth, oesophagus, larynx, stomach, liver, colon and rectum, as well as breast malignancies, since both acetaldehyde and alcohol itself contribute to this heightened risk (3).

There is strong evidence that alcohol causes cancer in seven places in the body, and probably others as well. These are the cancer of the oropharynx, larynx, oesophagus, liver, colon, rectum and breast, and current estimates suggest that alcohol-attributable cancers at these sites make up $5.8 \%$ of all cancer deaths globally $(28,29)$. Also, there is some evidence of reversibility of risk in laryngeal, pharyngeal and liver cancers when alcohol consumption ceases $(28,29)$. All types of alcoholic beverages are associated with an increased risk of cancer, which suggests that ethanol itself is the crucial compound that causes this effect (30).

The International Agency for Research for Cancer has classified alcohol consumption and acetaldehyde associated with alcohol consumption as carcinogenic for humans (group 1): the oral cavity, pharynx, larynx, oesophagus, colon, rectum, liver and female breast are places where cancer develops as a result of alcohol consumption (30). Although the process by which alcohol consumption exerts its carcinogenic effects has not been fully understood, credible occurrences include: a genotoxic effect of acetaldehyde; increased oestrogen concentration, which is important for breast carcinogenesis; a role as solvent of tobacco carcinogens; production of reactive oxygen species and nitrogen species; and change in folate metabolism (30). Furthermore, there is a linear increase in diseases as the intake of alcohol increases: oral, oesophagus, and colon cancer fall into this pattern, as very little is known about safe margins of alcohol consumption (30).

Given the linear dose-response relation between alcohol intake and risk of cancer, control of heavy drinking remains the main target for cancer control (30). In healthy subjects, European Code against Cancer recommends keeping daily consumption within two drinks for men and one drink for women (30). There is insufficient data to support the actually safe intake of alcohol as any level of alcohol consumption 
increases the risk of developing alcohol-related cancer (30).

The findings of a study on alcohol consumption and serum metabolite concentrations in young women revealed that alcohol was significantly associated with several serum metabolites such as the amino acid sarcosine, the omega- 3 fatty acid eicosapentaenoate, and the steroid 4- androsten-3beta, 17betadiol monosulfate were positively associated with alcohol intake (31). Furthermore, the findings of a study on light to moderate amount of lifetime alcohol consumption and risk of cancer in Japan revealed that light to moderate alcohol consumption appears to be associated with elevated cancer risks in Japan (32).

\section{Chronic obstructive pulmonary disease (COPD):}

Arvers has shown that there is a connection between COPD and alcohol consumption (33). Importantly, with a progressive desensitization of ciliary response, ethanol exposure reduces airway mucociliary clearance; as a result, this important innate primary defence mechanism which protects the lungs from the deleterious effects of different pollutants, allergens and pathogens, is weakened (33).

Chronic alcohol exposure alters the adaptative immune response to pathogens (decreasing the phagocytic function of macrophages) and leads to an inflammatory response (pro-inflammatory cytokines) (33). Also, respiratory function is impaired by alcohol misuse: asthma, chronic obstructive pulmonary disease, lung infections, and the acute respiratory distress syndrome are more frequent and severe (33). In addition to neurodevelopmental effects, alcohol consumption at high levels during pregnancy is associated with immunomodulation and premature birth (34). Premature birth, in turn, is associated with increased susceptibility to various infectious agents such as respiratory syncytial virus (RSV) (34). Hence, chronic maternal ethanol consumption during the third trimester of pregnancy alters innate immune gene expression in foetal lung (34). These alterations may underlie increased susceptibility of preterm infants exposed to ethanol in utero, to RSV and other microbial agents (34). Also, exposure to ethanol during the last trimester of pregnancy alters the maturation and immunity of the foetal lung (35). Hence, ethanol-mediated alterations in foetal lung maturation and immunity may explain the increased incidence of respiratory infections in neonates exposed to ethanol in utero (35).
The volatility of alcohol promotes the movement of alcohol from the bronchial circulation across the airway epithelium and into the conducting airways of the lung; prolonged and heavy exposure to alcohol impairs mucociliary clearance, may complicate asthma management, and likely worsens outcomes including lung function and mortality in COPD patients (36). Although smoking is the primary cause of lung cancer, a slightly greater risk of lung cancer was associated with the consumption of less or $=30 \mathrm{~g}$ alcohol/d than with no alcohol consumption. Alcohol consumption is also strongly associated with greater risk in male never smokers (37).

Chronic alcohol intake increased lung fibrosis in the bleomycin-model of lung injury, as this effect was related to increased production of transforming growth factor $\beta$ (TGF $\beta$ ) and expression of $\alpha$-smooth muscle actin suggests that the lung is a target for alcohol, and that chronic alcohol intake may predispose the lung to disrepair after injury (38). The overexpression of pro-fibrotic growth factors and pro-inflammatory cytokines, and the generation of oxidant stress may lead to lung cellular dysfunction, aberrant tissue remodelling and loss of lung function (38).

In addition to the classic consequences of endotoxemia associated with liver cirrhosis that were described several decades ago, important research in the last ten years has shown that cytokines may also induce damage in remote organs such as brain, bone, muscle, heart, lung, gonads, peripheral nerve and pancreas, as these effects are even seen in alcoholics without significant liver disease (39).

Crohn's disease: A European prospective cohort study (EPIC) found that there was no evidence of associations between alcohol use and the odds of developing either ulcerative colitis (UC) or Crohn's disease (CD) (40). Nevertheless, dietary guidelines for Crohn's disease and ulcerative colitis include nutritional deficiency screening, avoiding foods that worsen symptoms, eating smaller meals at more frequent intervals, drinking adequate fluids, avoiding caffeine and alcohol, taking vitamin/mineral supplementation, eliminating dairy if lactose intolerant, limiting excess fat, reducing carbohydrates and reducing high-fibre foods during flares (41).

Diabetes: Interestingly, light and moderate alcohol consumption was associated with a lower risk of type 2 diabetes (T2D), whereas heavy alcohol consumption was not related to the risk of T2D, but cau- 
tion must be taken as to what constitutes light and moderate drinking (42). In addition, excessive intake of alcohol may not only cause loss of metabolic control, but also annihilate the favourable effects on the cardiovascular system (43).

According to a study on alcohol consumption, diabetes risk and cardiovascular disease within diabetes, men consume more alcohol than women in populations with and without diabetes (44). Also, lightto-moderate alcohol consumption decreases the incidence of diabetes in the majority of the studies, whereas heavy drinkers and binge drinkers are at increased risk of developing diabetes (44). In addition, alcohol consumption may be a risk factor of diabetic lower extremity arterial disease (LEAD) in patients with T2D Mellitus (T2DM) (45). Hence, patients with T2DM are advised to stop drinking to prevent the onset of LEAD (45).

A study on alcohol consumption and the risk of T2D revealed that relative to combined abstainers, reductions in the risk of T2D were present at all levels of alcohol intake $<63 \mathrm{~g} /$ day, with risks increasing above this threshold, as peak risk reduction was present between 10-14 g/day at an 18\% decrease in hazards (46). Also, chronic alcohol consumption strongly increased the risk of T2D by increasing insulin resistance (IR), especially in men with low T2DGRS, highlighting the importance of refraining from drinking alcohol when making recommendations for healthy lifestyle habits to prevent diabetes (47). Furthermore, a study on occupational exposure to heavy metals, alcohol intake, and risk of T2D and prediabetes among male Chinese workers revealed that exposure to metal and heavy alcohol intake was associated with the risk of diabetes in a large cohort of male workers as there was a strong interaction between these two exposures in affecting diabetes risk. The risk of both T2D and prediabetes was significantly elevated with increasing number of standard drinks per week, years of drinking and lifetime alcohol consumption (48). Importantly, during adolescence, frequent alcohol consumption at levels reaching 5 or more drinks, 3-7 days/week, substantially increased the risk of diabetes in young adulthood; hence, heavy alcohol use during adolescence may increase the risk of diabetes in young adulthood (49).

Epilepsy: The findings from a systematic review and meta-analysis study on alcohol consumption, unprovoked seizures and epilepsy revealed that there is a strong and consistent association between alcohol consumption and epilepsy/unprovoked seizures (50). There was a dose-response relationship between the amount of alcohol consumed daily and the probability of the onset of epilepsy as individuals consuming an average of four, six, and eight drinks daily had an overall relative risk compared to non-drinkers (50). Several pathogenic mechanisms for the development of epilepsy in alcohol users were identified.

Most of the relevant studies found that a high percentage of alcohol users with epilepsy would qualify for the criteria of alcohol dependence (50). Importantly, two kinds of epileptic events are frequently related to alcohol consumption: 1 ) seizures triggered by alcohol withdrawal; often multiple, they occur within between 10 and 48 hours after discontinuing or reducing alcohol intake and can be followed by a delirium tremens; 2 ) recurring unprovoked seizures, which are usually rare, 1 or 2 yearly; the risk is increased for heavy drinkers but returns to normal for ex-drinkers (51). Seizures related to alcoholism are usually generalized tonicoclonic seizures with normal electroencephalogram (EEG) and CT-scan (51). When partial seizures are identified, they are attributed to preceding brain damage, head trauma or stroke (51).

Also, long-term alcohol intake increases the risk of epilepsy via activation of mammalian target of rapamycin (mTOR) signalling (52). Moreover, ethanolinduced mTOR activation may be dependent on the AKT-mTOR signalling pathway (52). The key molecules involved in AKT-mTOR signalling pathway may serve as potential targets in the treatment of epilepsy (52). In elderly patients, the most frequent causes of late-onset epilepsy seem to be cerebrovascular disease, head trauma and alcoholism (53). The findings from an experimental approach study on alcohol consumption and sudden unexpected death in epilepsy revealed that there is a possible association between alcohol abuse and sudden unexpected death in epilepsy (SUDEP) occurrence (54). Furthermore, the findings from a systematic review study of the risk factors associated with the onset and natural progression of epilepsy revealed that family history of epilepsy, history of febrile seizures, alcohol consumption, central nervous system (CNS) and other infections, brain trauma, head injury, perinatal stroke, preterm birth and three genetic markers are associated with the onset of epilepsy (55).

Heart disease and cardiovascular health: Heavy alcohol consumption can cause high blood pressure by triggering the release of certain hormones that 
Israel 0 Ayenigbara. Chronic Alcohol Use and Accompanying Noncommunicable Diseases. Croat Nurs J. 2020; 4(2): 227-242

cause constriction of blood vessels which adversely affect the heart (3). Furthermore, alcohol consumption has a major and complex impact on cardiovascular diseases, as both irregular and chronic heavy drinking occasions detrimentally impact most major cardiovascular disease categories, whereas light to moderate drinking has been associated with beneficial effects on ischemic heart disease and ischemic stroke (56).

Heavy drinking (more than 4 drinks per day) is associated with an increased risk of death and cardiovascular (CV) diseases (CVD) (57). Excessive alcohol intake trails behind only smoking and obesity among the three leading causes of premature deaths in the USA, as heavy alcohol use is a common cause of reversible hypertension, non-ischaemic dilated cardiomyopathy, atrial fibrillation (AF) and stroke (both ischemic and haemorrhagic) (57). Furthermore, the increased risks of heavy drinking, defined as three or more standard-sized drinks per day, are both cardiovascular (CV) and non-CV (58). CV risks include the following: (i) alcoholic cardiomyopathy (ACM), (ii) systemic hypertension, (iii) atrial arrhythmias, (iv) haemorrhagic stroke and probably ischaemic stroke (58).

In addition, alcohol consumption decreases myocardial contractility and induces arrhythmias and dilated cardiomyopathy, resulting in progressive cardiovascular dysfunction and structural damage (59). Alcohol, whether at binge doses or a high cumulative lifetime consumption, both of which should be discouraged, is clearly deleterious for the cardiovascular system, increasing the incidence of total and cardiovascular mortality, coronary and peripheral artery disease, heart failure, stroke, hypertension, dyslipidaemia and diabetes mellitus (59). A study on heavy alcohol consumption and its association with impaired endothelial function revealed that heavy alcohol consumption may be an independent risk factor of endothelial dysfunction in Japanese men (60). The findings from a cohort study on the association between alcohol consumption and risk of myocardial infarction (MI) and heart failure $(\mathrm{HF})$ revealed that alcohol consumption has divergent associations with $\mathrm{MI}$ and $\mathrm{HF}$, with an inverse association observed for MI but not HF (61). Furthermore, heavy drinking was associated with an increased HF risk in men (61). Importantly, women with moderate to heavy alcohol intake had a significantly increased risk of morbidity and total mortality compared with men in multiple subpopulations (62). Hence, control of alcohol intake should be considered for women, particularly for young women who may be susceptible to binge drinking (62).

Among East Asians, even moderate alcohol consumption can confer subclinical adverse effects on cardiac systolic functions, which was most pronounced in subjects carrying common variants in alcohol metabolizing genes (63). These findings challenge the notion of beneficial influences of less heavy ethanol consumption on the heart, especially among East Asians (63). In a study on the impact of past and current alcohol consumption patterns on progression of carotid intima-media thickness among women and men living with the human immunodeficiency virus (HIV) infection, the findings revealed that in both cohorts, 10-year heavy consumption was associated with statistically significant increases in carotid artery thickness, compared to abstinence (64). The long- term patterns of drinking at any level above abstinence were particularly significant for increases in intima-media thickness among men, with heavy consumption presenting with the greatest increase, and these findings suggest a potentially different window of risk among past and current heavy drinkers (64).

Immune system dysfunction: Drinking too much alcohol weakens the immune system, thereby making the body vulnerable to infectious diseases, such as pneumonia and tuberculosis, as alcohol causes changes in red blood cells, white blood cells and platelets (3). Furthermore, heavy alcohol consumption in association with tobacco smoke and a deficient diet causes changes in the metabolism and distribution of carcinogens; alterations in cell cycle behaviour such as cell cycle duration leading to hyperproliferation; and nutritional deficiencies, such as methyl-, vitamin E-, folate-, pyridoxal phosphate-, zinc- and selenium deficiencies and alterations of the immune system, eventually resulting in an increased susceptibility to certain virus infections such as hepatitis $B$ virus and hepatitis C virus (65).

Moderate alcohol consumption is associated with reduced inflammation and improved responses to vaccination while chronic drinking is associated with a decreased frequency of lymphocytes and increased risk of both bacterial and viral infections (66). Furthermore, acute alcohol inhibits, and chronic alcohol accelerates inflammatory responses (67). The proinflammatory effects of chronic alcohol play a major role in the pathogenesis of alcoholic liver disease and pancreatitis, but also affect numerous other organs 
and tissues (67). In addition to promoting proinflammatory immune responses, alcohol also impairs antiinflammatory cytokines (67).

Likewise, chronic alcohol exposure also interferes with the normal functioning of all aspects of the adaptive immune response, including both cell-mediated and humoral responses (67). The findings from a study on prenatal alcohol exposure and the developing immune system revealed that alcohol may have indirect effects on the immune system by increasing the risk of premature birth, which itself is a risk factor for immune-related problems (68). Animal studies suggest that alcohol exposure directly disrupts the development of the immune system (68).

Chronic alcohol abuse reduces the number of peripheral $\mathrm{T}$ cells, disrupts the balance between different T-cell types, influences T-cell activation, impairs Tcell functioning and promotes T-cell apoptosis (69). Likewise, chronic alcohol consumption also seems to cause the loss of peripheral B cells, while simultaneously inducing increased production of immunoglobulins (69). The levels of antibodies against liver-specific auto antigens are increased in patients with alcoholic liver disease and may promote alcoholrelated liver damage (69).

Finally, chronic alcohol exposure in utero interferes with normal T-cell and B-cell development, which may increase the risk of infections during both childhood and adulthood (69). The impact of alcohol on T cells and $B$ cells increases the risk of infections (e.g. pneumonia, HIV infection, hepatitis C virus infection and tuberculosis), impairs responses to vaccinations against such infections, exacerbates cancer risk and interferes with delayed-type hypersensitivity (69).

Liver diseases: Liver is the main organ responsible for metabolizing ethanol, and therefore the major victim of alcohol abuse (3). Ethanol and its bioactive products, acetaldehyde-acetate, fatty acid ethanol esters and ethanol-protein adducts, have been regarded as hepatotoxins that directly and indirectly exert their toxic effect on the liver (70). Importantly, alcoholic liver disease (ALD) is a leading cause of cirrhosis, liver cancer, and acute and chronic liver failure, and as such causes significant morbidity and mortality (71).

Alcohol-induced changes in the gastrointestinal tract (GIT) microbiota composition and metabolic function may contribute to the well-established link between alcohol-induced oxidative stress, intestinal hyper- permeability to luminal bacterial products and the subsequent development of alcoholic liver disease (ALD), as well as other diseases (72). In addition, clinical and preclinical data suggest that alcohol-related disorders are associated with quantitative and qualitative dysbiotic changes in the intestinal microbiota and may be associated with increased GIT inflammation, intestinal hyperpermeability, resulting in endotoxemia, systemic inflammation and tissue damage/ organ pathologies including ALD (72).

Furthermore, chronic alcohol consumption promotes diethylnitrosamine-induced hepatocarcinogenesis via immune disturbances as chronic alcohol consumption exacerbates DEN-induced hepatocarcinogenesis by enhancing protumor immunity, impairing antitumor immunity and aggravating hepatic pathological injury (73).

In assessing the role of alcohol during hepatic disease, and as a carcinogen, many of the deleterious effects of alcohol can be attributed to alcohol metabolism in hepatocytes (74). In addition to the direct effects of alcohol/alcohol metabolism on hepatocyte transformation, increasing evidence indicates that other intrahepatic and systemic effects of alcohol are likely to play an equally significant role in the process of hepatic tumorigenesis (74).

Malnourishment and vitamin deficiencies: Dysfunctional drinking leads to malnourishment and vitamin deficiencies (75). Furthermore, chronic alcoholic patients are frequently deficient in one or more vitamins, and the deficiencies commonly involve folate, vitamin B6, thiamine and vitamin A (76). Although inadequate dietary intake is a major cause of vitamin deficiency, other possible mechanisms may also be involved as alcoholism can affect the absorption, storage, metabolism and activation of many vitamins (76).

Malabsorption occurs frequently in chronic alcoholics, as alcoholics may malabsorb fat, nitrogen, sodium, water, thiamine, folic acid, vitamin B12 and D-xylose (77). Malabsorption occurs due to an abnormal luminal phase of digestion as well as a diffuse functional mucosal abnormality (77). Malabsorption may, therefore, contribute to clinically significant malnutrition, diarrhoea, folate-deficiency and abnormalities in tests of xylose and vitamin B12 absorption (77). Factors producing malabsorption in alcoholics include dietary folic acid and protein deficiency, pancreatic insufficiency, abnormalities of biliary secretions and direct effects of 
Israel 0 Ayenigbara. Chronic Alcohol Use and Accompanying Noncommunicable Diseases. Croat Nurs J. 2020; 4(2): 227-242

alcohol on the gastrointestinal tract, but many of the absorptive abnormalities are reversed when alcoholics are given a nutritious diet (77).

Also, chronic alcohol consumption leads to deficiency of this vitamin due to dietary inadequacy, intestinal malabsorption, decreased hepatic uptake and increased body excretion, mainly via urine, and decreased concentration of serum folic acid may occur in $80.5 \%$ of alcoholics (78). The cause of elevated concentrations of homocysteine in the serum of alcohol abusers is a deficiency of vitamins involved, such as vitamin B12 and pyridoxal phosphate, as disturbance of folic acid and homocysteine metabolism in alcohol abusers can lead to serious clinical consequences such as macrocytic and megaloblastic anaemia and neurological disorders, as megaloblastic anaemia occurs in about half of alcohol abusers with chronic liver diseases (78). In turn, a high level of homocysteine in blood is associated with an increased risk of cardiovascular diseases, ashyperhomocysteinemia is an independent risk factor that favours the occurrence of acute coronary syndromes in patients with coronary heart disease (78).

The findings from a study on nutritional deficiencies in chronic alcoholics revealed that over-malnutrition is infrequent in this group of chronic alcoholics; specific vitamin deficiencies are present in a substantial proportion of patients and are more likely related to alcohol consumption (79). Importantly, among healthy, well-nourished, postmenopausal women, moderate alcohol intake may diminish vitamin B12 status (75).

Mood disorders (bipolar disorder, cyclothymic disorder and depression): Mood disorders and alcohol use are common in the general population and often occur together (80). Mood disorders, particularIy bipolar disorder, act as unique risk factors for first alcohol use in the general population and show significant interactions with developmental timing (80).

The findings from a study on anxiety disorders and first alcohol use in the general population revealed that early onset anxiety disorders significantly predict first alcohol use in the general population, and this relationship appears to be related to change over time, which points to the need for developmentally appropriate and integrated prevention programs that target anxiety and alcohol use together (81).

There is also a causal linkage between alcohol use disorders and major depression, such that increasing involvement with alcohol consumption increases the risk of depression (82). Importantly, alcohol abuse, but not dependence, precedes many mood and anxiety disorders, and if the primary disorder does in fact play a causative or contributing role in the development of the subsequent disorder, this role can best be described as "temporally distal" (83).

The findings from a comparative study on the burden of cyclothymia on alcohol dependence revealed that CT traits in alcohol dependents seems to influence whether subjects engage earlier in pathological alcohol use and present particular alcohol-related problems, in particular Cloninger type II alcoholism phenotype (84).

Osteoporosis and bone malformation: Chronic alcohol consumption, particularly during adolescence and young adulthood, can dramatically affect bone health, and it may increase the risk of developing osteoporosis, with a loss of bone mass, later in life (85). Likewise, alcohol consumption is a risk factor for osteoporosis based on frequent findings of low bone mass, decreased bone formation rate and increased fracture incidence in alcoholics (85).

Alcohol has been shown to reduce bone formation in healthy humans and animals and to decrease proliferation of cultured osteoblastic cells (85). Secondary causes of osteoporosis include hypercortisolism, hyperthyroidism, hyperparathyroidism, alcohol abuse and immobilization (86). Importantly, heavy alcohol consumption is generally associated with decreased bone mineral density (BMD), impaired bone quality and increased fracture risk (87). Bone remodelling is the principal mechanism for maintaining a healthy skeleton in adults, and dysfunction in bone remodelling can lead to bone loss and/or decreased bone quality (87). Decrease in bone mass and strength following alcohol consumption is mainly due to bone remodelling imbalance, with a predominant decrease in bone formation (88). However, recent studies have shown new mechanisms by which alcohol may act on bone remodelling, including osteocyte apoptosis, oxidative stress, and Wnt signalling pathway modulation (88).

The findings from a study on the effect of chronic alcohol consumption on the longitudinal growth of the tibia and bone quality parameters in young rats under an experimental setup revealed that chronic consumption of alcohol affected the bones of young rats, making them weaker and osteopenic (89). In addition, long bones were shorter, suggesting interference with growth (89). 
The findings from a study on voluntary chronic heavy alcohol consumption in male rhesus macaques revealed that voluntary chronic heavy alcohol consumption reduces cancellous bone formation in lumbar vertebra by decreasing osteoblast-lined bone perimeter, a response associated with an increase in bone marrow adiposity (90).

Pancreatitis: Overconsumption of alcohol can lead to pancreatitis, a painful inflammation of the pancreas that often requires hospitalization (91). Chronic abuse of alcohol, but not occasional alcoholic intoxication, also causes pancreatic damage (92).

Alcohol is metabolized by the pancreas via both oxidative and non-oxidative metabolites; hence, alcohol and its metabolites produce changes in the acinar cells, which may promote premature intracellular digestive enzyme activation, thereby predisposing the gland to autodigestive injury (93). Pancreatic stellate cells (PSCs) are activated directly by alcohol and its metabolites and also by cytokines and growth factors released during alcohol-induced pancreatic necroinflammation (93). Activated PSCs are the key cells responsible for producing the fibrosis of alcoholic chronic pancreatitis (93).

The findings from a study on the impact of alcohol consumption on pancreatic diseases revealed that high alcohol intake was associated with a higher risk of pancreatitis (around 2.5\%-3\% among heavy drinkers and $1.3 \%$ among non-drinkers) (94). Furthermore, about $70.5 \%$ of pancreatitis cases are due to chronic heavy alcohol consumption, and although this incidence rate differs between countries, it is clear that the risk of developing pancreatitis increases with increasing doses of alcohol and the average of alcohol consumption (94).

Ulcers and gastrointestinal problems: Heavy drinking can cause problems with the digestive system, such as acid reflux, heartburn and inflammation of the stomach lining, known as gastritis (3). When alcohol is consumed, the alcoholic beverage first passes through the various segments of the gastrointestinal (Gl) tract (95). Accordingly, alcohol may interfere with the structure as well as the function of Gl-tract segments. For instance, alcohol can impair the function of the muscles separating the oesophagus from the stomach, thereby favouring the occurrence of heartburn (95). Alcohol-induced damage to the mucosal lining of the oesophagus also increases the risk of oesophageal cancer (95). In the stomach, alcohol interferes with gastric acid secretion and with the activity of the muscles surrounding the stomach (95). Similarly, alcohol may impair muscle movement in the small and large intestines, contributing to diarrhoea frequently observed in alcoholics (95). Moreover, alcohol inhibits the absorption of nutrients in the small intestine and increases the transport of toxins across the intestinal walls, effects that may contribute to the development of alcohol-related damage to the liver and other organs (95).

In addition, excessive alcohol consumption (even a single episode) can result in duodenal erosions and bleeding, and mucosal injury in the upper jejunum (96). An increased prevalence for bacterial overgrowth in the small intestine may contribute to functional and/or morphological abnormalities of this part of the gut and also to non-specific abdominal complaints in alcoholics (96). The mucosal damage caused by alcohol increases the permeability of the gut to macromolecules and this facilitates the translocation of endotoxin and other bacterial toxins from the gut lumen to the portal blood, thereby increasing the liver's exposure to these toxins and, consequently, the risk of liver injury (96).

Examples of more pronounced organ injury which can occur even following a single episode of heavy drinking are tears in the mucosa at the junction of the oesophagus and the stomach (Mallory-Weiss lesion) and haemorrhagic erosions in the stomach and/ or the duodenum which may lead to massive bleeding (97). In the small intestine, alcohol abuse interferes with the absorption of glucose, amino acids, lipids, water, sodium and vitamins (especially thiamine and folic acid), as this inhibition of absorption of nutrients may contribute to nutritional deficiencies frequently observed in alcoholics (97).

Acute alcohol ingestion can also damage the mucosa in the upper region of the small intestine and may lead to the disruption of the tips of the villi (97). Various diseases of the GIT, including tumours, may be related to excessive alcohol intake and the relationship between alcohol abuse and hepatic and pancreatic damage is well established (98). Importantly, alcohol-induced changes in the GIT microbiota composition and metabolic function may contribute to the well-established link between alcohol-induced oxidative stress, intestinal hyperpermeability to luminal bacterial products and the subsequent development of alcoholic liver disease (ALD), as well as other diseases (72). 
Clinical and preclinical data suggest that alcoholrelated disorders are associated with quantitative and qualitative dysbiotic changes in the intestinal microbiota and may be associated with increased GIT inflammation, intestinal hyperpermeability resulting in endotoxemia, systemic inflammation and tissue damage/organ pathologies including ALD (72).

The findings from a study on the effect of chronic alcohol consumption on gut bacteria composition revealed that daily alcohol consumption for 10 weeks alters colonic mucosa-associated bacterial microbiota composition in rats (99). This data showed for the first time that daily alcohol consumption can affect colonic microbiome composition and suggests that dysbiosis may be an important mechanism of alcohol-induced endotoxemia (99).

\section{Conclusions}

Heavy consumption of alcohol causes many health problems to the drinker and the society at large. As a major public health problem, $5.1 \%$ of the global burden of morbidity and injuries are attributable to alcohol usage alone. This study has shown that chronic alcohol use is either a single or joint risk factor for Alzheimer's disease and dementia, arthritis, brain malfunction, cancers (oropharynx, larynx, oesophagus, liver, colon, rectum and the breast), chronic obstructive pulmonary disease (COPD), diabetes, epilepsy, heart disease and cardiovascular diseases, immune system dysfunction, malnourishment and vitamin deficiencies, mood disorders, bipolar disorder and depression, osteoporosis and bone malformation, pancreatitis, ulcer and gastrointestinal problems, and may also be a risk factor for Crohn's disease. These findings are background information. Hence, more and precise long-term cohort studies are necessary for a better understanding of the occurrences and epidemiology of noncommunicable diseases that result from chronic alcohol use.

Generally, it is strongly recommended that any form of alcohol consumption should be stopped. If this is not possible, the level of alcohol consumption should be reduced to the barest minimum to prevent any form of alcohol-related diseases.

\section{Acknowledgements}

I wish to extend my gratitude to the researchers whose studies are discussed in this article. I would also like to thank the anonymous reviewers for their valuable comments.

\section{References}

1. World Health Organization. Alcohol; Key facts. 2018. Available from: https://www.who.int/news-room/factsheets/detail/alcohol Accessed:15.06.2020.

2. National Institute on Alcohol Abuse and Alcoholism. Health risks and benefits of alcohol consumption (PDF). 2000. Available from: https://pubs.niaaa.nih.gov/publications/arh24-1/05-11.pdf Accessed:15.06.2020.

3. Davis K. Ten health risks of chronic heavy drinking. 2018. Available from: https://www.medicalnewstoday.com/articles/297734.php_Accessed:15.06.2020.

4. Office for National Statistics. Alcohol Deaths: Rates stabilise in the UK. 2014. Available from: https:// www.ons.gov.uk/Accessed:15.06.2020.

5. Cancer Research UK. Alcohol and cancer. 2013. Available from: https://www.cancerresearchuk.org/about-us Accessed:15.06.2020.

6. British Broadcasting Cooperation [BBC]. Alcohol 'kills one in 20 Scots'. 2009. Available from: http://news. bbc.co.uk/2/hi/uk_news/scotland/8126129.stm Accessed:15.06.2020.

7. Lister $\mathrm{S}$. The price of alcohol: an extra 6,000 early deaths a year. 2009. Available from: https://www.thetimes.co.uk/article/the-cost Accessed:15.06.2020.

8. UK Research and Innovation. Alcohol causes more than half of all premature deaths in Russian adults. 2009. Available from: https://mrc.ukri.org/news/browse/alcohol-causes-more-than-half-of-all-prematuredeaths-in-russian-adults/ Accessed:15.06.2020.

9. Centre for Disease Control. Excessive Alcohol Use. 2019. Available from: https://www.cdc.gov/chronicdisease/resources/publications/factsheets/alcohol.htm Accessed:15.06.2020.

10. Woody C, Belleroche J. Drink, Drugs and Dependence: From Science to Clinical Practice (1st ed.). London: Routledge; 2002. p.19-20.

11. Shield KD, Parry C, Rehm J. Chronic Diseases and Conditions Related to Alcohol Use. Alcohol Res. 2013;35(2):155-73. 
12. Rehm J, Baliunas D, Borges GLG, Graham K, Irving H, Kehoe T, et al. The Relation Between Different Dimensions of Alcohol Consumption and Burden of Disease: An Overview. Addiction. 2010;105(5):817-43.

13. Parry CD, Patra J, Rehm J. Alcohol Consumption and Non-Communicable Diseases: Epidemiology and Policy Implications. Addiction. 2011;106(10):1718-24.

14. Breslow RA, Mukamal KJ. Measuring the Burden-Current and Future Research Trends: Results from the NIAAA Expert Panel on Alcohol and Chronic Disease Epidemiology. Alcohol Res. 2013;35(2):250-9.

15. Venkataraman A, Kalk N, Sewell G, Ritchie CW, LingfordHughes N. Alcohol and Alzheimer's Disease- Does Alcohol Dependence Contribute to Beta-Amyloid Deposition, Neuroinflammation and Neurodegeneration in Alzheimer's Disease?. Alcohol Alcohol. 2017;52(2):151-8.

16. Heymann D, Stern Y, Cosentino S, Tatarina-Nulman O, Dorrejo JN, Gu Y. The Association between Alcohol Use and the Progression of Alzheimer's disease. Curr Alzheimer Res. 2016;13(12):1356-62.

17. Andrews SJ, Goate A, Anstey KJ. Association between alcohol consumption and Alzheimer's disease: $A$ Mendelian randomization study. Alzheimers Dement. 2020;16(2):345-53.

18. Xu W, Wang H, Wan Y, Tan C, Li J, Tan L, et al. Alcohol Consumption and Dementia Risk: A Dose-Response Meta-Analysis of Prospective Studies. Eur J Epidemiol. 2017;32(1):31-42.

19. Wei J, Qin L, Fu Y, Dai Y, Wen Y, Xu S. Long-term Consumption of Alcohol Exacerbates Neural Lesions by Destroying the Functional Integrity of the Blood-Brain Barrier. Drug Chem Toxicol. 2019;1-8.

20. Ki-Min H, Lee J, Ju JH, Park S, Kwok S. Alcohol consumption as a predictor of the progression of spinal structural damage in axial spondyloarthritis: data from the Catholic Axial Spondyloarthritis COhort (CASC0). Arthritis Res Ther. 2019;21(1):187.

21. Green A, Shaddick G, Charlton R, Snowball J, Nightingale $A$, Smith $C$, et al. Modifiable risk factors and the development of psoriatic arthritis in people with psoriasis. Br J Dermatol. 2020;182(3):714-20.

22. Hedström AK, Hössjer O, Klareskog L, Alfredsson L. Interplay between alcohol, smoking and HLA genes in RA aetiology. RMD Open. 2019;5(1):e000893.

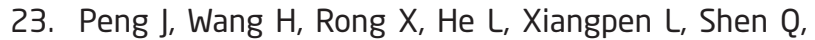
Peng Y. Cerebral Hemorrhage and Alcohol Exposure: $A$ Review. Alcohol Alcohol. 2020;55(1):20-7.

24. Wilhelm CJ, Guizzetti, M. Fetal Alcohol Spectrum Disorders: An Overview from the Glia Perspective. Front IntegrNeurosci. 2015;9:65.

25. Fuente-Ortega ED, Plaza- Briceño W, Vargas-Robert S, Haeger P. Prenatal Ethanol Exposure Misregulates Genes Involved in Iron Homeostasis Promoting a Maladaptation of Iron Dependent Hippocampal Synaptic Transmission and Plasticity. Front Pharmacol. 2019;10:1312.
26. Mashhoon Y, Czerkawski C, Crowley DJ, Cohen-Gilbert JE, Sneider JT, Silveri MM. Binge alcohol consumption in emerging adults: anterior cingulate cortical 'thinness' is associated with alcohol use patterns. Alcohol Clin Exp Res. 2015;38(7):1955-64.

27. Cservenka A, Brumback T. The Burden of Binge and Heavy Drinking on the Brain: Effects on Adolescent and Young Adult Neural Structure and Function. Front Psychol. 2017:8:1111.

28. Connor J. Alcohol Consumption as a Cause of Cancer. Addiction. 2015;112(2):222-8.

29. López-Lázaro M. A Local Mechanism by Which Alcohol Consumption Causes Cancer. Oral Oncol. 2016;62:14952.

30. Testino G. The Burden of Cancer Attributable to Alcohol Consumption. Maedica (Bucur). 2011;6(4):313-20.

31. Dorgan JF, Jung S, Dallal CM, Zhan M, Stennett CA, Zhang Y, et al. Alcohol Consumption and Serum Metabolite Concentrations in Young Women. Cancer Causes Control. 2020;31(2):113-26.

32. Zaitsu M, Takeuchi T, Kobayashi Y, Kawach I. Light to Moderate Amount of Lifetime Alcohol Consumption and Risk of Cancer in Japan. Cancer. 2020;126(5):1031-40.

33. Arvers P. Alcohol Consumption and Lung Damage: Dangerous Relationships. Rev Mal Respir. 2018;35(10):103949.

34. Lazic T, Wyatt TA, Matic M, Meyerholz DK, Grubor B, Gallup JM, et al. Maternal Alcohol Ingestion Reduces Surfactant Protein A Expression by Preterm Fetal Lung Epithelia. Alcohol. 2007;41(5):347-55.

35. Lazic T, Sow FB, Geelen AV, Meyerholz DK, Gallup JM, Ackermann MR. Exposure to Ethanol During the Last Trimester of Pregnancy Alters the Maturation and Immunity of the Fetal Lung. Alcohol. 2011;45(7):673-80.

36. Sisson JH. Alcohol and Airways Function in Health and Disease. Alcohol. 2007;41(5):293-307.

37. Freudenheim JL, Ritz J, Smith-Warner SA, Albanes D, Bandera EV, van den Brandt PA, et al. Alcohol Consumption and Risk of Lung Cancer: A Pooled Analysis of Cohort Studies. Am J Clin Nutr. 2005;82(3):657-67.

38. Roman J. Chronic Alcohol Ingestion and Predisposition to Lung "Cirrhosis". Alcohol Clin Exp Res. 2014;3(2):312-5.

39. González-Reimers E, Santolaria-Fernández F, MartínGonzález MC, Fernández- Rodríguez CM, QuinteroPlatt G. Alcoholism: A Systemic Proinflammatory Condition. World J Gastroenterol. 2014;20(40):14660-71.

40. Bergmann MM, Hernandez V, Bernigau $W$, Boeing $H$, Chan SSM, Luben R, et al. No Association of Alcohol Use and the Risk of Ulcerative Colitis or Crohn's Disease: Data from a European Prospective Cohort Study (EPIC). Eur J Clin Nutr. 2017;71(4):512-18.

41. Brown AC, Rampertab SD, Mullin GE. Existing Dietary Guidelines for Crohn's Disease and Ulcerative Colitis. Expert Rev Gastroenterol Hepatol. 2011;5(3):411-25.

42. Li XH, Yu F, Zhou Y, He J. Association between Alcohol Consumption and the Risk of Incident Type 2 Diabe- 
tes: A Systematic Review and Dose- Response MetaAnalysis. Am J Clin Nutr. 2016;103(3):818-29.

43. Van de Wiel A. Diabetes Mellitus and Alcohol. Diabetes Metab Res Rev. 2004;20(4):263-7.

44. Polsky S, Akturk HK. Alcohol Consumption, Diabetes Risk, and Cardiovascular Disease within Diabetes. Curr Diab Rep. 2017;17(12):136.

45. Yang S, Wang S, Yang B, Zheng J, Cai Y, Yang Z. Alcohol Consumption Is a Risk Factor for Lower Extremity Arterial Disease in Chinese Patients with T2DM. J Diabetes Res. 2017:2017:8756978.

46. Knott C, Bell S, Britton A. Alcohol Consumption and the Risk of Type 2 Diabetes: A Systematic Review and Dose-Response Meta- analysis of More Than 1.9 Million Individuals from 38 Observational Studies. Diabetes Care. 2015;38(9):1804-12.

47. Yu H, Wang T, Zhang R, Yan J, Jiang F, Li S, et al. Alcohol Consumption and Its Interaction With Genetic Variants Are Strongly Associated With the Risk of Type 2 Diabetes: A Prospective Cohort Study. Nutr Metab (Lond). 2019;16:64.

48. Yang $\mathrm{A}$, Hu X, Liu S, Cheng $\mathrm{N}$, Zhang $\mathrm{D}$, Li J, et al. Occupational Exposure to Heavy Metals, Alcohol Intake, and Risk of Type 2 Diabetes and Prediabetes among Chinese Male Workers. Chronic Dis Transl Med. 2019;5(2):97-104.

49. Liang W, Chikritzhs T. Alcohol Consumption during Adolescence and Risk of Diabetes in Young Adulthood. Biomed Res Int. 2014;2014:795741.

50. Samokhvalov AV, Irving H, Mohapatra S, Rehm J. Alcohol Consumption, Unprovoked Seizures and Epilepsy: A Systematic Review and Meta-Analysis. Epilepsia. 2010;51(7):1177-84

51. Baulac M, Laplane D. Alcohol and Epilepsy. Rev Prat. 1990;40(4):307-11.

52. Fu X, Guo Z, Gao C, Chu Q, Li J, Ma H, et al. Long-Term Alcohol-Induced Activation of Mammalian Target of Rapamycin Is a Key Risk Factor of Epilepsy. Med Sci Monit. 2016;22:3975-80.

53. Pierzchała K, Machowska-Majchrzak A. Late Onset of Epilepsy. Wiad Lek. 2003;56(11-12):577-81.

54. Scorzai CA, Cysneiros RM, Arida RM, Terra VC, Machado HR, de Almeida AG, et al. Alcohol Consumption and Sudden Unexpected Death in Epilepsy: Experimental Approach. Arq Neuropsiquiatr. 2009;67(4):1003-6.

55. Walsh S, Donnan J, Fortin Y, Sikora L, Morrissey A, Collins K, et al. A Systematic Review of the Risks Factors Associated With the Onset and Natural Progression of Epilepsy. Neurotoxicology. 2017;61,64-77.

56. Rehm J, Roerecke M. Cardiovascular Effects of Alcohol Consumption. Trends Cardiovasc Med. 2017;27(8):534-8.

57. O'Keefe EL, DiNicolantonio JJ, O'Keefe JH, Lavie C]. Alcohol and CV Health: Jekyll and Hyde J-Curves. Prog Cardiovasc Dis. 2018;61(1):68-75.

58. Klatsky AL. Alcohol and Cardiovascular Diseases: Where Do We Stand Today? . Intern Med. 2015;278(3):238-50.
59. Fernández-Solà J. Cardiovascular Risks and Benefits of Moderate and Heavy Alcohol Consumption. Nat Rev Cardiol. 2015;12(10):576-87.

60. Tanaka A, Cui R, Kitamura A, Liu K, Imano H, Yamagishi $\mathrm{K}$, et al. Heavy Alcohol Consumption Is Associated With Impaired Endothelial Function. J Atheroscler Thromb. 2016;23(9):1047-54.

61. Larsson SC, Wallin A, Wolk A. Contrasting Association between Alcohol Consumption and Risk of Myocardial Infarction and Heart Failure: Two Prospective Cohorts. Int J Cardiol. 2017;231:207-10.

62. Zheng Y, Lian F, Shi Q, Zhang C, Chen Y, Zhou Y, et al. Alcohol Intake and Associated Risk of Major Cardiovascular Outcomes in Women Compared With Men: A Systematic Review and Meta-Analysis of Prospective Observational Studies. BMC Public Health. 2015;15:773.

63. Hung C, Chang S, Chang S, Chi P, Lai Y, Wang S, et al. Genetic Polymorphisms of Alcohol Metabolizing Enzymes and Alcohol Consumption Are Associated With Asymptomatic Cardiac Remodeling and Subclinical Systolic Dysfunction in Large Community- Dwelling Asians. Alcohol Alcohol. 2017;52(6):638-46.

64. Chichetto NE, Plankey MW, Abraham AG, Sheps DS, Ennis N, Chen X, et al. The Impact of Past and Current Alcohol Consumption Patterns on Progression of Carotid Intima- Media Thickness Among Women and Men Living With HIV Infection. Alcohol Clin Exp Res. 2019;43(4):695-703.

65. Pöschl G, Seitz HK. Alcohol and Cancer. Alcohol Alcohol. 2004;39(3):155-65.

66. Barr T, Helms C, Grant K, Messaoudi I. Opposing Effects of Alcohol on the Immune System. Prog Neuropsychopharmacol Biol Psychiatry. 2016;65:242-51.

67. Szabo G, Saha B. Alcohol's Effect on Host Defense. Alcohol Res. 2015;37(2):159-70.

68. Gauthier TW. Prenatal Alcohol Exposure and the Developing Immune System. Alcohol Res. 2015;37(2):279-85.

69. Pasala S, Barr T, Messaoudi, I. Impact of Alcohol Abuse on the Adaptive Immune System. Alcohol Res. 2015;37(2):185-97.

70. Rocco A, Compare D, Angrisani D, Zamparelli MS, Nardone G. Alcoholic Disease: Liver and Beyond. World J Gastroenterol. 2014;20(40):14652-9.

71. Stickel F, Datz C, Hampe J, Bataller R. Pathophysiology and Management of Alcoholic Liver Disease: Update 2016. Gut Liver. 2017;11(2):173-88.

72. Engen PA, Green SJ, Voigt RM, Forsyth CB, Keshavarzian A. The Gastrointestinal Microbiome: Alcohol Effects on the Composition of Intestinal Microbiota. Alcohol Res. 2015;37(2):223-36.

73. Yan $G$, Wang $X$, Sun $C$, Zheng $X$, Wei $H$, Tian $X$, et al. Chronic Alcohol Consumption Promotes Diethylnitrosamine-Induced Hepatocarcinogenesis via Immune Disturbances. Sci Rep. 2017;7(1):2567.

74. McKillop IH, Schrum LW. Role of Alcohol in Liver Carcinogenesis. Semin Liver Dis. 2009;29(2):222-32. 
75. Laufer EM, Hartman TJ, Baer DJ, Gunter EW, Dorgan JF, Campbell WS, et al. Effects of Moderate Alcohol Consumption on Folate and Vitamin B (12) Status in Postmenopausal Women. Eur J Clin Nutr. 2004;58(11):1518-24.

76. Hoyumpa AM. Mechanisms of Vitamin Deficiencies in Alcoholism. Alcohol Clin Exp Res. 1986;10(6):573-81.

77. Green PH. Alcohol, Nutrition and Malabsorption. Clin Gastroenterol. 1983;12(2):563-74.

78. Cylwik B, Chrostek L. Disturbances of Folic Acid and Homocysteine Metabolism in Alcohol Abuse. Pol MerkurLekarski. 2011;30(178):295-9.

79. Glória L, Cravo M, Camilo ME, Resende M, Cardoso JN, Oliveira AG, et al. Nutritional Deficiencies in Chronic Alcoholics: Relation to Dietary Intake and Alcohol Consumption. Am J Gastroenterol. 1997;92(3):485-9.

80. Birrell L, Newton NC, Teesson M, Slade T. Early Onset Mood Disorders and First Alcohol Use in the General Population. J Affect Disord. 2016;200:243-9.

81. Birrell L, Newton NC, Teesson M, Tonks Z, Slade T. Anxiety Disorders and First Alcohol Use in the General Population. Findings from a Nationally Representative Sample. J Anxiety Disord. 2015;31:108-13.

82. Boden JM, Fergusson DM. Alcohol and Depression. Addiction. 2011;106(5):906-14.

83. Falk DE, Yi H, Hilton ME. Age of Onset and Temporal Sequencing of Lifetime DSM-IV Alcohol Use Disorders Relative to Comorbid Mood and Anxiety Disorders. Drug Alcohol Depend. 2008;94(1-3):234-45.

84. Pombo S, Figueira ML, da-Costa NF, Ismail F, Yang G, Akiskal K, et al. The Burden of Cyclothymia on Alcohol Dependence. J Affect Disord. 2013;151(3):1090-6.

85. Turner RT. Skeletal Response to Alcohol. Alcohol Clin Exp Res. 2000;24(11):1693-701.

86. Glaser DL, Kaplan FS. Osteoporosis. Definition and Clinical Presentation. Spine (Phila Pa 1976). 1997;22(24 Suppl):12S-16S.

87. Gaddini DW, Turner RT, Grant KA, Iwaniec UT. Alcohol: A Simple Nutrient With Complex Actions on Bone in the Adult Skeleton. Alcohol Clin Exp Res. 2016;40(4):657-71.
88. Maurel DB, Boisseau N, Benhamou CL, Jaffre C. Alcohol and Bone: Review of Dose Effects and Mechanisms. Osteoporos Int. 2012;23(1):1-16.

89. Rosa RC, Rodrigues WF, Miguel CB, Cardoso FAG, Espindula AP, Oliveira CJF. Et al. Chronic Consumption Of Alcohol Adversely Affects The Bone Of Young Rats. Acta Ortop Bras. 2019;27(6):321-4.

90. Kahler-Quesada AM, Grant KA, Walter NAR, Newman N, Allen MR, Burr DB, et al. Voluntary Chronic Heavy Alcohol Consumption in Male Rhesus Macaques Suppresses Cancellous Bone Formation and Increases Bone Marrow Adiposity. Alcohol Clin Exp Res. 2019;43(12):2494-503.

91. Schneider A, Singer MV. Alcoholic Pancreatitis. Dig Dis. 2005;23(3-4):222-31.

92. Pezzilli R. Alcohol Abuse and Pancreatic Diseases: An Overview. Recent Pat Inflamm Allergy Drug Discov. 2015;9(2):102-6.

93. Apte MV, Pirola RC, Wilson JS. Mechanisms of Alcoholic Pancreatitis. J Gastroenterol Hepatol. 2010;25(12):181626.

94. Herreros-Villanueva M, Hijona $E$, Bañales JM, Cosme A, Bujanda L. Alcohol Consumption on Pancreatic Diseases. World J Gastroenterol. 2013;19(5):638-47.

95. Bode C, Bode JC. Alcohol's Role in Gastrointestinal Tract Disorders. Alcohol Health Res World. 1997;21(1):76-83.

96. Bode C, Bode JC. Effect of Alcohol Consumption on the Gut. Best Pract Res Clin Gastroenterol. 2003;17(4):575-92.

97. Bode JC, Bode C. Alcohol, the Gastrointestinal Tract and Pancreas. Ther Umsch. 2000;57(4):212-9.

98. Federico A, Cotticelli G, Festi D, Schiumerini R, Addolorato G, Ferrulli $A$, et al. The Effects of Alcohol on Gastrointestinal Tract, Liver and Pancreas: EvidenceBased Suggestions for Clinical Management. Eur Rev Med Pharmacol Sci. 2015;19(10):1922-40.

99. Mutlu E, Keshavarzian A, Engen P, Forsyth CB, Sikaroodi $M$, Gillevet $P$. Intestinal Dysbiosis: A Possible Mechanism of Alcohol-Induced Endotoxemia and Alcoholic Steatohepatitis in Rats. Alcohol Clin Exp Res. 2009;33(10):1836-46. 


\section{KRONIČNA UPOTREBA ALKOHOLA I POPRATNE NEZARAZNE BOLESTI}

\section{Sažetak}

Uvod. Prekomjeran i kroničan unos alkohola predstavlja učestalo, kontinuirano i ustrajno konzumiranje alkoholnih pića tijekom dužeg razdoblja. Prekomjerna konzumacija alkohola uzrokuje brojne zdravstvene probleme pojedincu, ali i cijelome društvu, te se više od $5,1 \%$ globalnog moraliteta i bolesti pripisuje isključivo konzumaciji alkohola.

Cilj. Svrha je ovog istraživanja sustavnim pregledom literature i detaljnim opisom pojava prepoznati nezarazne bolesti koje se vežu uz kroničnu konzumaciju alkohola.

Metode. Sustavni pregled literature kojim se utvrdilo koje su nezarazne bolesti povezane s konzumacijom alkohola proveden je upotrebom Googlea, Medlinea i baza podataka velikih međunarodnih zdravstvenih organizacija. Ključne riječi upotrijebljene pri pretraživanju bile su alkoholizam i kronična konzumacija alkohola. Te se pojmove povezalo s pojavama i rizikom od nezaraznih bolesti. Istraživanja uključena u ovaj pregled obuhvaćaju klinička ispitivanja, metaanalize, kontrolirana klinička ispitivanja sa slučajnim uzorkom te pregledne članke.

Rezultati. Istraživanje je pokazalo da kronična konzumacija alkohola predstavlja jedan od čimbenika rizika za Alzheimerovu bolest i demenciju, artritis, nepravilnu moždanu funkciju, rak (najčešće rak ždrijela, jednjaka, jetre, debelog crijeva, rektuma i dojke), kroničnu opstruktivnu bolest pluća, dijabetes, epilepsiju, bolesti srca i kardiovaskularne bolesti, disfunkciju imunološkog sustava, pothranjenost i nedostatak vitamina, poremećaje raspoloženja, bipolarni poremećaj i depresiju, osteoporozu i deformaciju kosti, upalu gušterače te čireve i gastrointestinalne probleme.

Zaključak. Ovi uvidi predstavljaju pozadinski sadržaj jer upućuju na određene nezarazne bolesti povezane s kroničnom konzumacijom alkohola, stoga je potrebno više preciznih dugoročnih kohortnih istraživanja kako bi se bolje razumjelo pojave i epidemiologiju nezaraznih bolesti koje su posljedica kronične konzumacije alkohola.

Ključne riječi: obrazac, kronično, konzumacija alkohola, nezarazne bolesti 